\title{
Post-Revolutionary Tunisian Youth Art: The Effect of Contestation on the Democratization of Art Production and Consumption
}

\author{
Mounir Saidani
}

\section{Introduction}

Since the sudden removal of President Ben Ali from power in Tunisia in January 2011, the country has witnessed an unprecedented number of political reforms; however, the process of social change, as crucial as it seems, has proven slower and more painful than expected. The political changes - for example, the increasing number of political parties, the succession of electoral referendums, a new constitution and new elites in power - are more apparent than any social transformation. The emergence of new social movements raising new demands on new issues gets little coverage and cultural movements even less. I argue here that Tunisian society can be characterized by a prevailing political centrism and an overvaluation of the recent political changes. PostBen Ali political processes have attracted disproportionate attention at the expense of cultural phenomena, especially given how much the latter contribute to social change.

My aim in this chapter is to discuss this issue from a Bourdieusian perspective, examining processes of cultural change and restructuration and how they reconfigure other fields and practices (Bourdieu 1979, 1991, 1992). In general, cultural changes are less speedy and less remarkable than other aspects of social change; nevertheless, I consider that the current evolution in the Tunisian situation (2010-2015) is a very specific one. Indeed, the country witnessed an unprecedented wave of demonstrations, turmoil and disorder that succeeded in creating a strong social movement, leading to popular uprisings and eventually political revolution. This was, and continues to be, so wide, deep and harsh that the average speed of cultural change is ever increasing.

In what follows, I discuss these issues at two coinciding levels. Firstly, I examine the structural factors and changes that have expanded the practices and opportunities of producing and consuming art among young people in the post-Ben Ali era. The important roles of information and communication technology (ICT) are given special attention, as they provide relatively inexpensive 
platforms for artistic expression and better opportunities of reaching wider audiences than before. Secondly, I discuss the content of art production by members of the young generation, focusing especially on expressions of anger and contestation transmitted through rap music and graffiti. What are the objectives of these artists? Is the expansion of such expression to new and wider dimensions among their goals? Do these changes have the side effect of democratizing art production and consumption? Does such a democratization entail a new world vision?

Methodologically this chapter is based on my personal observations of, and participation in, the historic processes of Tunisian revolution since 2010. I have a longstanding academic interest in the field of young people's art production in Tunisia (Saidani 2015), especially among those between 18 and 30 years of age. Hence, since the revolution, I have observed a number of youth activities in different parts of the country, including villages and rural areas, gathering stories of, and conducting interviews with, young artists in Tunisia. Here I analyse some of these materials together with additional data collected from social networking sites and mass media.

\section{A Changing Cultural Landscape}

As shown by Gana (2012), growing numbers of young Tunisians are experiencing new forms and styles of art production. This is especially true of urban youth as actors, and rap music and graffiti in terms of genre - trends which were already detectable before the 2010 uprising. In recent years, these artistic genres have gained considerable attention in the media and in public discourses, both scientific and popular. Small bands and groups of urban youth, particularly young males committed to the Internet and new ITCs, were constituted among secondary school pupils, especially in lower-middle-class neighbourhoods at the peripheries of the country's main towns. Some of these groups or individuals could even hold spectator events attracting audiences of five to seven thousand, especially at small town festivals, although the bigger and more valuable venues are often monopolized by more established older artists (see also Bourdieu 1991).

Some of the newly-formed groups then began to experiment with ICTs as a way to distribute their art. One can describe the two main prevailing orientations of that time via the opposition between the rap song entitled "Passepartout" produced by Balti (30 years old in the summer of 2010) and one called "President of the Country" produced by El General (19 years old in the autumn of 2010). The first piece, released on YouTube in the first weeks of the summer 
of 2010 - that is, some three months before the launch of the social movement in December 2010 - contained a very harsh critique of teenage girls' behaviour from a moralistic point of view. The lyrics paint a picture of hard-up girls spending their nights in bars and restaurants with wealthy males until the early hours of daylight, when they take taxis to their poor neighbourhoods on the west side of the capital (Balti 2011). The second piece, released on YouTube by the very beginning of December 2010 demonstrations, contains the same level of anger yet the critique is directed at the President 'whose people' are starving and oppressed by the police. At the beginning of the video, the President asks a poor pupil in a poor primary school if he has something to say to him. The deep and somehow apprehensive silence of the young boy is very expressive. The lyrics announce that the singer is aware that his fate will be catastrophic because of his boldness in crossing the line with this song (El General 2011).

These examples show that even before the revolution there was diversity, antagonism and opposition among young artists. Nevertheless, expressing social and political criticism was a very significant step towards a change in the conditions of art production and dissemination. Not surprisingly, the political regime sought to seize upon this new phenomenon. Some of the rappers were invited to attend the annual ceremonies celebrating the anniversary of the November 7, 1987, coup which brought Zine Alabidine Ben Ali to power, an increasingly salient event during the five last years of his rule that ended on January 14, 2011. Some of them were urged to do this and they accepted, arguing that otherwise they would not be allowed to perform.

There is some evidence that the democratization process of conditions of art production and consumption was not devoid of shortcomings. Some of the limitations on the process were imposed from the outside: political restrictions due to the repressive cultural policies of the regime, as well as technological challenges due to the lack of financial resources - a great number of young artists had no access to professional studios in order to record their music. Other limitations were produced internally: the majority of the artists were inexperienced, fell to commercial temptation and struggled with oppositional trends within the emerging community. Until the last months of 2013, in spite of a few attempts, Tunisian rappers could not organize themselves into a union or even an association.

In the post-Ben Ali era, Tunisian rappers have continued to fight for liberty of expression and to expand its limits. Despite the gradual democratization of political processes (free parliamentary and presidential elections, a new constitution, the free constitution of political parties and associations), they have often faced legal action and jail terms for what they do. In 2013, Alaa Eddine Yakoubi, a rap singer working under the name Weld El Kenz, published a song 
titled "El Boulicia Kleb" (Cops are Dogs). As in other Arab dialects, in Tunisian to be like a dog is to be without values and to profit from a person in a 'predominant' position in order to oppress or humiliate someone. A dog is a subaltern acting for its superiors, performing their orders with blind fidelity. This is not especially new in Tunisia; even in 2008, one could see the letters 'A.C.A.B' scrawled on the walls of every town, an acronym for 'All Cops Are Bastards'. Putting this global English acronym on Tunisian town walls, especially in $\mathrm{Tu}-$ nis, the capital, and in other big cities, somehow connected the graffitists to international youth contestation movements. One youth community was especially active in this field, namely, football club supporters, often organized in groups with special self-designations: Ultras, Fighters, Winners, Brigade Rouge, to name a few. On weekends, when the games took place, they used to clash with security forces in and around the stadiums. But to voice that cops are all bastards in a song, to put it on YouTube (March 2013) hardly a month after the assassination of Leftist leader and spokesman for the Patriot Democratic Movement Party, Chokri Belaid, and then to perform it with Ahmed Ben Ahmed (alias 'Вв G') at international festivals supported and promoted by the Ministry of Culture, such as Hammamet in August 2013, was clearly seen by state authorities as unacceptable. The following summer, in Morocco, the Tunisian rap singer was enthusiastically asked to sing "El Boulicia Kleb" by Moroccan teenagers and also older young people who had heard it on YouTube. 'National' barriers to the diffusion of art products no longer exist.

The singers of "El Boulicia Kleb" were eventually charged and tried for the "insulting" lyrics. The first trial took place in June 2013, resulting in jail sentences of two years which were later reduced to six months and suspended. On August 30, 2013, a second trial sentenced the two singers, who were missing at the first one because they had not received the summons, to 21 months in jail. On September 5, 2013, in a report entitled "Tunisia: Rappers Sentenced to Prison String of Prosecutions for Artwork, Writing, Lyrics Deemed 'Insulting”' (Human Rights Watch 2013), Human Rights Watch wrote: "The sentences of a year and nine months in prison, which violate their right to free expression, are the latest in a string of similar prosecutions." Even the Prime Minister considered that there was no link between this "appeal to the hatred and to death of policemen" and freedom of expression. Weld El Kenz went into hiding, but reappeared for a further trial on December 5,2013 . He and the members of his group were charged with "harming" the police, "affecting good moral standards" and "causing injury to civil servants". In this trial, they were exonerated and cleared of the charges.

It is of importance that the police unions, created in the first post-revolution weeks, have become increasingly powerful in Tunisia. Constituting a huge net 
of labour unions, thousands of police officers were, in consequence, more able to organize protests against the officials of their supervisory minister. On October 18, 2013, in an official burial ceremony for victims of "terrorist attacks perpetrated by Salafist armed groups", the President, the Prime Minister and the Head of the Constitutional Assembly were designated unwanted people and were urged to back off. The following week, five of the officials of one of the security unions presumed to have led this action were suspended from work. In response, the police unions organized strikes and sit-ins to air their social and professional demands. On several occasions they have said that they are 'against official anti-terrorism strategies' and that 'they have their own, which is the only efficient way to defeat terrorists'. Their lobbying was so efficient that they could be seen on TV talk shows and giving newspapers interviews to 'explain' their actions. Furthermore, they publish declarations and statements about the security situation in the country on their Facebook official page; in justification of these actions and discourses, they claim they "are in a very practical field", insinuating that they are the only ones who can have a say and therefore should control what is allowed to be said about security policies. In such an atmosphere, every critique is easily seen as an offense "against those who are effectively defending the nation".

In an interview I conducted with one of the members of a graffiti group named Ahl Elkehf, (The Inhabitants of the Cave, an allusion to The Seven Sleepers), told me that they consider themselves 'an underground' and 'oppositional' art group. Because of that, even after 2011, they used to apply their graffiti in the last minutes of darkness before daylight. Another graffiti group, Zwawla (Poor Men), experiences similar limitations to freedom of expression and subversion as rappers such as Weld El Kenz. Zwawla is composed of 20-24-year-old graphic arts students, some of whom are settled in the capital pursuing university studies while others remain in Gabes, the town whence the group originated. Like many others, Gabes is a southern industrial town rich with new youth sub-cultural expression. Zwawla's graffiti commonly consists of slogans such as, "keep away from the poor", "the people are fed up and...". In a newspaper interview, one of the graffiti artists, a young man, said that once when he was writing the latter phrase on a wall, he was apprehended by a police officer, but when he was in the police station, he was told, "Yes, that is the truth. You can go and finish your graffiti." This is likely to be an exception, however. During December 2012 and January 2013, Zwawla group members were prosecuted after they were arrested by police officers when painting because "their ravages" caused harm to "private property". This took place in the early hours of the morning, when the two young men thought that they were safe under the protection of darkness. After a series of trials, rather than going to 
jail they were sentenced to pay a fine of about 70 us dollars. Support for them was expressed all around the country. Students, school pupils and young people in general committed to the new art expression and became its animators, painting their messages on the walls of bigger and smaller towns, and on the 'electronic walls' of Facebook and other social networking sites.

The trials and their aftermath were a crucial moment in the process of shaping young subversive identity, as analysed by Božilović (2010) and Dagnaud (2011). However, as with young post-revolutionary Tunisian artists, democratizing artistic creation and diffusion was not an actual goal. The transformation in the conditions of art production and reception took place from below, with political authorities facing these new manifestations of youth rebellion using the police control methods of show scenes and trials. The challenge was to have the right to protest, to say that "enough is enough", "the world is witnessing a very deep crisis" and "we need a new world and we deserve it" as in the song by Hamzaoui and Kafon. This new generation was struggling for new spaces to express their views on their own terms.

The selected empirical examples discussed here show that the first goal of young people experimenting with artistic expression was to enlarge their audience, to make it ever wider, especially among young people. To achieve such a goal they had to reformulate the rules of social management of youthful expectation (Borup et al. 2006; Bickel 2003). Yet the side effect of broadening their audiences was to enlarge the boundaries of the art field through disturbing its functioning rules. This has a lot to do with the rights of expression enshrined in official policies and even more with the equilibrium within the art field itself.

\section{Clashes}

Access to the means of disseminating art products is a crucial issue of democratization. For new Tunisian artists, social networking sites such as Facebook and YouTube currently supply the most preferred modes of distributing and consuming both rap music and graffiti images although graffiti artists also choose town walls close to train stations, the walls of secondary schools, colleges and faculties and viaduct pillars. These means of making young and angry art available challenge old rules of ranking popular and mass arts. In the light of the works of Di Maggio (1987), one can say that this is an aspect of the mobility of artworks.

The reactions of the older musical leadership were illustrative of its rejection of this reconstruction of the field. On December 2, 2012, the Vice General Secretary of the National Union of Tunisian Professional Singers, a trade union 
affiliated to the Tunisian General Confederation of Labour (CGTT), announced that he was resolutely against those who are "trying to denigrate their master and to bring strange behaviour and values to the musical arena". This was the tone of his discourse on an Attounissia TV talk show entitled "People Talk" and on several occasions after that on the radio and in newspapers. Bendir Man, one of the targeted new musicians, produced a song to respond to "the accusations". The title of the satirical song cites the name of the Vice General Secretary, and the lyrics strongly belittle him Bendirman (2014).

The main objection of older generations of musicians is that those "boys" have not had any training and are, musically speaking, ignorant. On a TV program (March 26, 2014), a young rapper is insulted by an older female singer who denigrates his song, "Houmani" ("Quarterly": as in, what should be done in our quarter), saying that she cannot listen to it in the morning. He responds that she is "fake" (using the English word). In the same program, his friend and co-singer, on being asked about the opinions of their song's detractors says that, in spite of his respect for the older singers, he challenges them to do what he has done (Hamzaoui 2013). He is referring to the fact that the song he and his friend produced and posted on YouTube has been watched and listened to by eight million people within a time span of little more than six months, harvesting on average more than 4,400 views per day: a precedent in the history of Tunisian music. Clearly, one can claim that a 'new' popular music has been born (Bennett, 2008), while the emergence of new genres of political rap in Tunisia has meanwhile created new forms of intergenerational tensions. From a different angle, at stake are also new controversies over artistic taste, over what is considered good and/or appropriate music (Greenblatt 2009).

Yet these controversial young rappers had overlooked that their claims for freedom of expression in the practice of "their" art are also applicable to others in other artistic areas. Now movie and theatre actors are also engaging in rap singing and when three of these newcomers to the scene had some success, they were considered 'intruders' by established rappers. Formulating the rules of the game and the positions of each artist is one of the controversies within the field of rap production and distribution, and also one side of the process of democratization and reshaping the artistic field as a whole. Hence, one can say that in post-revolutionary Tunisia social contradictions are reflected in the realm of the arts, in opposing and controversial social categorizations and in the applications of art (Bourdieu 1979). In this sense, the transformations in the arts are to be understood as an aspect of profound social change. Yet the new situation is far from being stabilized. The rap controversy is placing young artists in opposition to older ones on the one hand, and young singers from different orientations on the other. The very existence of a considerable audience 
for all parties shows that the spectators, even when they seem similar, do not have a unified vision or unified taste (Buckingham 2008). Indeed, they are increasingly eclectic and hybrid, an aspect of the label of "cultural chameleons" which Daenekindt (2013) has applied to them.

One cannot speak about one youth community of taste but of several such communities and it is also clear that conditions of art production and consumption are less and less a product of a single 'focal centre' of control that can dictate the rules of the game. Politically speaking, production is less likely to be controlled by a government weakened by the political turbulence the country has witnessed since the end of Ben Ali's presidency on January 14, 2011. Financially speaking, the process of art production and reception has increasingly left the hands of the professional studios, the companies and the old guard who once held prominent positions in the field. As noted above, the song "Houmani" had been seen by more than eight million people in the six months after its launching, a massive number for a Tunisian artist whose country has 10 million inhabitants. Yet the cost of making the clip did not exceed 250 Tunisian Dinars (130 USD). Young singers' work no longer needs huge investment to bring it to the public as ICT networks create shortcuts across the old circuits of diffusion of artwork with new rap and graffiti products, gradually forming specific communities based on their consumption. Even though these are only virtually connected groups of people, one can consider them communities whose unity is based on shared artistic taste. In the Tunisian case, cultural changes are being introduced to public life by the younger generations yet the massive youth participation in the revolution did not bring substantive changes to their lives, despite their being in a majority, especially at the social level.

\section{A Social Narration of Inequalities?}

The meetings of the National Dialogue, held in late January 2014, brought to the round table some 12 parties, from the so-called Religious Right to the leftist Popular Front. The four strongest civil society associations - the Tunisian Workers General Union (UGTT), the Tunisian Industry and Trade Union (UTICA), the Tunisian Human Rights League, and the Bar Association - were involved in the dialogue. It seems that the Mahdi Jomaa government was engaged in a political process which was bringing neoliberal technocrats to power. A wide range of young people saw themselves as betrayed by the parties and by the strong civil society associations. The Religious Right former opposition party, Ennahdha, is one of the strongest parties yet is increasingly seen as a recycling mechanism seeking to resuscitate the dominance of the former ruling Rassemblement Constitutionnel Démocratique Party in official 
political life. The subsequent governments are becoming less tolerant of all protest, whether social, political or cultural. Yet the widespread disappointment has enhanced youthful manifestations of anger and rejection in every field of expression. The distressed situation of teenage pupils, students and unemployed college and university graduates, especially in poor and lowermiddle-class neighbourhoods and small and medium-sized towns, requires creative, innovative response. The disillusionment of young people, coupled with their aspirations, fears, hopes and other mixed feelings (Bickel 2003) are producing innovative and subversive imaginaries that could shape a new vision of the world inspired by youth - and inspiring them in turn (Kirmse 2010).

In a radio interview, one of the two rappers, Med Amine Hamzaoui, who sang the song mentioned above, said that his musician friend Ahmed Laabidi, alias Kafon, recorded his 'part', the first section, and several weeks later it was up to him to finish the job. Meanwhile, Kafon was sentenced to prison for a year for drug consumption, though released some nine months later under the regime of 'conditional freedom'. A civil society association initiative named Prisoner $5^{2}$ had addressed an open letter to the Prime Minister seeking the reduction of the sentence for drug consumption as it is determined in the 1992 law amendment number 52 . Some half an hour after midnight on March 19 , 2014, the neighbourhood of the released prisoner was in a state of euphoria with dozens of young people singing the first quartets of the henceforth wellknown rap piece. In May 2014, a new episode of tracking protesters took place. A highly subversive blogger, Azizi Amami, was also arrested for drug consumption. A large youth campaign of solidarity succeeded in forcing the judge to release him due to 'procedural non-conformity', yet this could also be seen as an official tactic to prevent potential 'snowball effects' of youthful protest. Amami's supporters are the same leagues, associations, groups and other revolutionary and subversive youth networks that supported the families of the martyrs of the revolution, young rap singers and young graffitists. They seem to respond by deliberate politicization of the cases, as if they were looking for a fight, and are generally activists seeking to hold on to the revolutionary struggle after being disappointed by political parties including those from the left wing. From this perspective, one can observe a detailed sociology of the disappointed expectations of activist youth (Bickel 2003).

\section{Conclusion}

Since 2011, subversive youth cultures have continued to promote new practices in the field of art production and diffusion in Tunisia. Many Tunisians, young people especially, hold the view that the original goals, aspirations and 
promises of the Tunisian revolution have not been fulfilled. Young musicians and rap artists have played crucial roles in introducing new genres of political dissent, expressing anger and frustration about the political situation in the country. Five years on, the social context is increasingly gloomy. The 'controlled depreciation' of the official currency, although supported by the central bank, the resulting inflation are making life more difficult for ordinary people. Even what are largely considered the most valuable achievements of the revolution, that is, freedom and liberty, are threatened. The 'National Consensus' turned out to be a conciliation between two right wing parties, the Islamist Ennahdha and the recycled former ruling elite Nidaa Tounes.

Young art producers, in protesting against the ancient game within the art field, have demonstrated that they are likely to feel the gloominess of the situation and to be wary of it to a greater degree than any other layer of the population. Seeking new spaces for expressing their views, feelings and attitudes, they also come to seek a new world. Aiming to make art production cheaper, easier and less professionally monopolized, they are making rap songs and graffiti more accessible to a greater number of young people. By causing art diffusion to become wider, deeper and less geographically and socially monopolized, the conditions of art reception are becoming less elitist and more popular. These are certainly aspects of a painful democratization of art production and consumption.

The new means of expression, closely connected to innovation in ICTs, were the preferred weapons of these young art producers in reaching their goals of enhanced visibility. Consequently, the tone of their rap and graffiti can also be seen as an indication, a thermometer of the popular sentiments simmering in post-Ben Ali Tunisia. Even though the democratization of art production was no more than an unintended consequence of youthful involvement in the art world, it has permitted young people to voice a subversive vision of the world that claims that the crisis of the society is a structural one, requiring radical changes.

\section{References}

Balti. 2011. "Passe Partout". Song. Youtube video, 4:45. Posted by Ezzeddine Sassi, 26 May. https://www.youtube.com/watch?v=42Y79YjaSPk (accessed January 27, 2017).

Bendir Man. 2014 “Ah Ya mokdad”. Song. Youtube video, 2:14. Posted by Seifallah Jlassi, 1 February. https://www.youtube.com/watch?v=l2evBioaXdU (accessed January 27, 2017).

Bennett, Andy. 2008. "Towards a cultural sociology of popular music." Journal of Sociology $44(4): 419-432$. 
Bickel, J.-F. 2003. "Quelques jalons pour une sociologie de l'attente." In L'avenir. Attentes, projets, (dés) illusions, ouvertures, edited by S. Cavalli and J.P. Fragnière, 1-12. Lausanne: Réalités sociales.

Borup, Mads, Nik Brown, Kornelia Konrad, and Harro Van Lente. 2006. "The Sociology of Expectations in Science and Technology." Technology Analysis \& Strategic Management 18 (3/4) : 285-298.

Bourdieu, Pierre. 1979. La Distinction Critique sociale du jugement. Paris: Éditions de Minuit.

Bourdieu, Pierre. 1992. Les règles de l'art. Genèse et structure du champ littéraire. Paris: Deuil.

Bourdieu, Pierre. 1991 “Le champ littéraire." Actes de la recherche en sciences sociales 89 (1): $3-46$.

Božilović, Nikola. 2010. "Youth Subcultures and subversive Identities." Acta Universitatis 9(1): $45^{-5}$, University of Niš, Serbia.

Buckingham, David. 2008. "Introducing Identity", in, David Buckingham, Youth, Identity, and Digital Media, Cambridge, MA: The MIT Press, 1-24.

Daenekindt, Stijn. 2013. "Cultural chameleons: Social mobility and cultural practices in the private and the public sphere." Acta Sociologica 56 (4): 309-324.

Dagnaud, Monique. 2011. Génération Y, les jeunes et les réseaux sociaux, de la dérision à lasubversion, Presses de Sciences-Po.

DiMaggio, Paul. 1987. "Classification in Art." American Sociological Review 54 (4): $440-455$.

El General. 2011. "President of the country." Song. Youtube video, 3:59. Posted by anon2get, 11 January. https://www.youtube.com/watch?v=P1BCstqKZWo (accessed January 27,2017 ).

Gana, Nouri. 2012. "Rap and Revolt in the Arab World." Social Text 30 (4113): 25-53.

Greenblatt, Stephen (ed.). 2009. Cultural Mobility: A Manifesto, Cambridge University Press.

Hamzaoui, Kafon. 2013. "Houmani." Song. Youtube video, 4:10. 14 September. Posted by Hamzaoui Med Amine, 14 September. https:/www.youtube.com/ watch?v=mz3p3a4EiXA (accessed January 27, 2017).

Human Rights Watch. 2013. "Tunisia: Rappers Sentenced to Prison. String of Prosecutions for Artwork, Writing, Lyrics Deemed 'Insulting', September 5, 2013. https:// www.hrw.org/news/2013/o9/05/tunisia-rappers-sentenced-prison (accessed January 25,2017$)$.

Kirmse, Stefan. 2010. "In the marketplace for styles and identities: globalization and youth culture in southern Kyrgyzstan." Central Asian Survey 29 (4): 389-403.

Saidani, Muneer. 2015. "Metamorphoses of the Cultural Field in Revolutionary Tunisia." Berkeley Journal of sociology, March 10, 2015. http://berkeleyjournal.org/2015/03/ metamorphoses-of-the-cultural-field-in-revolutionary-tunisia/ (accessed January 27, 2017). 